\title{
The determination of standard Gibbs energies of transfer of cations across the nitrobenzene/water interface using a three-phase electrode
}

\author{
Fritz Scholz *, Rubin Gulaboski, Karolina Caban ${ }^{1}$ \\ Ernst-Moritz-Arndt-Universität Greifswald, Institut für Chemie und Biochemie, Soldmannstraße 23, D-17489 Greifswald, Germany
}

Received 11 July 2003; received in revised form 8 September 2003; accepted 8 September 2003

Published online: 26 September 2003

\begin{abstract}
A three-phase electrode consisting of a droplet of a nitrobenzene solution of iron(III) tetraphenyl porphyrine chloride (Fe(III)TPP-Cl) attached to a graphite electrode and immersed in an aqueous electrolyte solution was applied to determine the standard Gibbs energies of transfer of cations between water and nitrobenzene. The reduction of Fe(III)-TPP-Cl prompts the transfer of the cations from the aqueous to the organic phase. The system is chemically and electrochemically reversible.
\end{abstract}

(C) 2003 Elsevier B.V. All rights reserved.

Keywords: Cation transfer; Liquid|liquid interface; Lipophilicity; Three-phase electrode; Iron(III) tetraphenyl porphyrine chloride

\section{Introduction}

Since the lipophilicity is one of the most important parameters for quantitative structure activity and property relationships, the design of drugs significantly depends on the accuracy of lipophilicity determinations. The usual measure of the lipophilicity of a compound $i$ is its partition coefficient: $P_{i}=c_{i}(\mathrm{o}) / c_{i}(\mathrm{aq})$. For single ions, it is connected with the standard potential of ion transfer by the relation $P_{i}=\exp \left(z_{i} F \Delta \phi_{\mathrm{aq}_{i}}^{\mathrm{o}^{\theta}} / R T\right)$ and it is related to the standard Gibbs energy of ion transfer by $P_{i}=\exp \left(-\Delta G_{\mathrm{aq} i}^{\mathrm{o}^{\theta}} / R T\right) ;\left(\Delta G_{\mathrm{aq} i}^{\mathrm{o}^{\theta}}=-z_{i} F \Delta \phi_{\mathrm{aq} i}^{\mathrm{o}^{\theta}}\right)$. While the lipophilicity of neutral compounds is relatively easy to determine by different partition techniques [1], the determination of the lipophilicity of single ions is still not a trivial work. Until recently, four electrode voltammetric measurements at the interface of two immiscible electrolyte solutions were the only tool for measuring the lipophilicity of single ions [1-11]. The weakness of this

\footnotetext{
${ }^{*}$ Corresponding author. Tel.: +49-3834-864-450; fax: +49-3834-864451.

E-mail address: fscholz@mail.uni-greifswald.de (F. Scholz).

${ }^{1}$ On leave from Warsaw University.
}

technique is mainly due to the presence of electrolytes in both the organic and the aqueous phases. This limits significantly the accessible potential window [3]. Moreover, non-polarizability of some interfaces such as water|$n$-octanol or other water|organic solvent interfaces renders the usage of ITIES measurements to some solvents, mainly nitrobenzene (NB), dichloroethane (DCE) and nitrophenyloctyl ether (NPOE) [1-3].

The recent introduction of the three-phase electrode approach [12] has overcome some of the limitations of the four-electrode experiments, and led to significant progress in lipophilicity determinations of a large number of inorganic [13-15], and organic ions [13-20] across different liquid|liquid interfaces, such as water|NB $[12-14,16,17,19]$, water $\mid n$-octanol $[15,20]$, water|menthol [18], water|DCE [12], and water|nitrophenylnonyl ether [21].

In the three-phase electrode experiments [12], an electroactive lipophilic neutral compound is dissolved in an organic solvent that does not contain any deliberately added electrolyte. When a droplet of this solution is attached to the working electrode and submerged in an aqueous electrolyte solution, the created charges in the organic liquid (due to the electrode reaction of the 
electroactive compound) must be compensated by transfer of counter ions across the interface of the adjacent liquid phases in order to maintain the electroneutrality of the organic phase. We have shown that the standard potential of ion transfer across the liquid|liquid interface can be deduced from the formal potential of the voltammograms that portray the coupled electron transfer at the electrode|organic solvent interface and ion transfer at the organic solvent|water solution interface [12-20]. A similar approach for monitoring the ion transfer across liquid|liquid interface was explored by Compton and co-workers [21-25], where the redox reactions of electroactive organic liquids have been studied in three-phase electrode arrangements. The thin-film voltammetry method of Anson and co-workers [26-28] is suitable for studying the electron transfer between reactants located at the opposite sides of the liquid|liquid interface, but it is not appropriate for quantification of the ion transfers (for extended comments see [13]). A three-electrode configuration was also used by Girault and co-workers [29] to follow the cation transfer across a liquid|liquid interface. In this approach an indirect polarisation of the liquid|liquid interface has been achieved via the redox reactions of an equimolar $\mathrm{Fe}(\mathrm{III}) / \mathrm{Fe}(\mathrm{II})$ couple, yet, the presence of electrolytes in both phases and the absence of three-phase junction have made this experiment fundamentally different from that of Compton and Scholz.

Here, for the first time we are presenting the capabilities of the three-phase electrode approach for following the transfer of cations across the water|organic solvent interface completely analogous to the previously reported case of anion transfer. Earlier, a three-phase electrode was already used for studying the cation transfer across the water|NB interface utilizing the reaction of iodine dissolved in NB [19]. However, due to the complexity of the entire mechanism (kinetic and thermodynamic control), and due to the reactivity of iodine towards many organic compounds [19], that approach has only a limited applicability.

\section{Experimental}

A $0.1 \mathrm{~mol} / 1$ solution of iron(III) tetraphenyl porphyrin chloride (Fe(III)-TPP-Cl) (see formula) (Sigma-Aldrich, Germany) was prepared by dissolution in nitrobenzene or DCE, respectively. All other chemicals were products of Merck or Sigma-Aldrich and were used as purchased. All salts were dissolved in distilled water of MilliQ purity, and all the solutions were saturated with NB or DCE, respectively. A droplet of the organic solution of Fe(III)-TPP-Cl of $1 \mu$ l-in-volume was attached to the working electrode surface and thereafter immersed in the aqueous chloride or nitrate solutions of different cations. A three-phase junction was always present between the three phases (graphite electrode, organic solution, aqueous electrolyte solution). Square-wave (SW) and cyclic voltammograms were recorded using the commercial electrochemical measuring system AUTOLAB (PGSTAT 10, Eco-Chemie, Utrecht, The Netherlands). A conventional threeelectrode voltammetric cell was used. The working electrode was a paraffin impregnated graphite electrode (PIGE) with a radius of $2 \mathrm{~mm}$, the reference electrode was a $\mathrm{Ag} \mid \mathrm{AgCl}$ (sat. $\mathrm{NaCl}$ ), while a $\mathrm{Pt}$ wire served as counter electrode. After each experiment the PIGE was cleaned by polishing it on a fine carborundum paper. Typical parameters for SWV were (if not specified otherwise): SW frequency $f=10 \mathrm{~Hz}, \mathrm{SW}$ amplitude $E_{\mathrm{sw}}=50 \mathrm{mV}$, scan increment $\mathrm{d} E=1 \mathrm{mV}$, and starting potential $E_{\mathrm{s}}=+0.3 \mathrm{~V}$ vs. $\mathrm{Ag} \mid \mathrm{AgCl}$. Cyclic voltammetric measurements were performed in order to check the reversibility of the overall process (at scan rates varying from 10 to $600 \mathrm{mV} / \mathrm{s}$ ). Consecutive cycling (at least 10 cycles) provided information on the stability of the entire system. For the measurements in non-aqueous solutions a conventional three-electrode cell was used with $\mathrm{Pt}$ as a working electrode, while the reference $\mathrm{Ag} / \mathrm{AgCl}$ electrode was separated from the organic solutions by a Vycor type membrane.

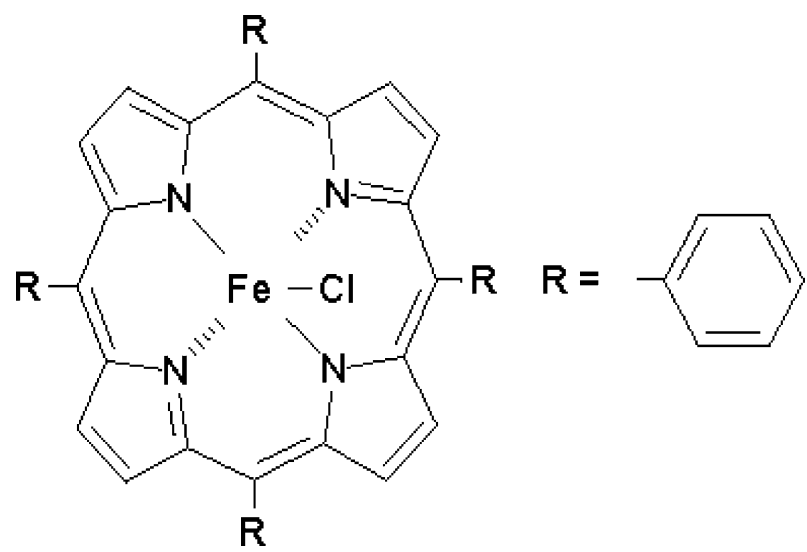

\section{Results and discussion}

The basic principles of the three-phase electrode approach are presented in Scheme 1. The overall process of electron transfer occurring across the electrode|organic solvent interface and simultaneous ion transfer at the aqueous solution|organic solvent interface can be written as follows:

$\mathrm{Ox}_{(\mathrm{o})}+\mathrm{Cat}_{(\mathrm{aq})}^{+}+\mathrm{e}^{-} \leftrightarrows \operatorname{Red}_{(\mathrm{o})}^{-}+\mathrm{Cat}_{(\mathrm{o})}^{+}$

(Here $\mathrm{Ox}$ is $\mathrm{Fe}(\mathrm{III})$-TPP-Cl and Red is [Fe(II)-TPP$\mathrm{Cl}]^{-}$.)

If no kinetic constrains exist with respect to the electron and ion transfer, the thermodynamic treatment 


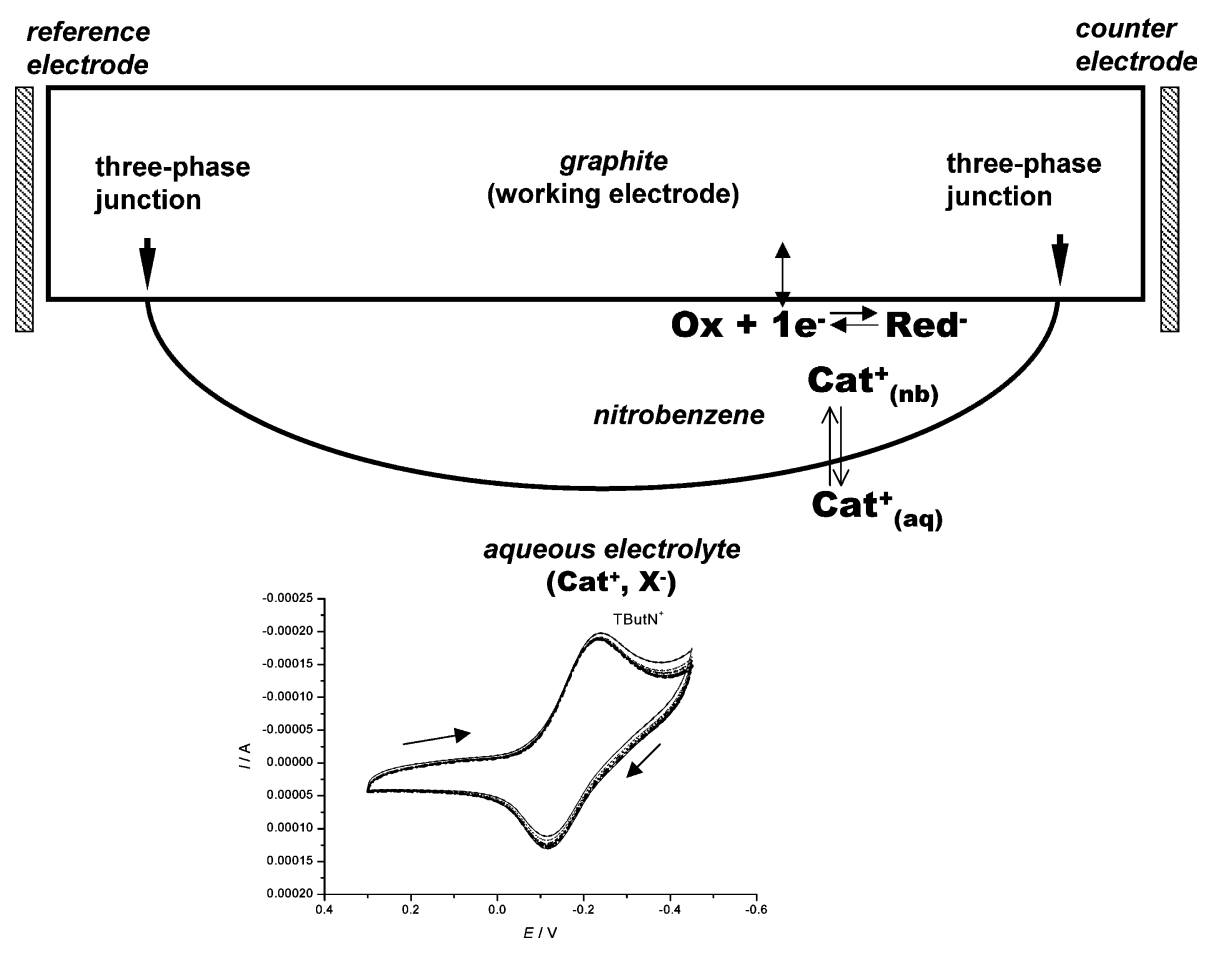

Scheme 1. Scheme of the three-phase electrode approach utilising a cation transfer across the water|organic solvent interface. Inset: cyclic voltammograms (10 cycles) of Fe(III)-TPP-Cl for TBA ${ }^{+}$cations being transferred from water to nitrobenzene $(v=100 \mathrm{mV} / \mathrm{s})$.

applied to reaction (I) leads to the following form of the Nernst equation:

$$
\begin{aligned}
E= & E_{\mathrm{Ox}_{(\mathrm{o})}^{\theta} \mid \operatorname{Red}_{(\mathrm{o})}^{-}}+\Delta \phi_{\mathrm{aq}^{\mathrm{o}^{\theta}}}^{\mathrm{Cat}^{+}}+\frac{R T}{F} \\
& \times \ln \left(\frac{c(\mathrm{Ox})_{(\mathrm{o})} c\left(\mathrm{Cat}^{+}\right)_{(\mathrm{aq})}}{c\left(\operatorname{Red}^{-}\right)_{(\mathrm{o})} c\left(\mathrm{Cat}^{+}\right)_{(\mathrm{o})}}\right) .
\end{aligned}
$$

In a first approximation, the activities in the Nernst equation have been replaced by concentrations. Since the concentration of the cations in the aqueous phase does not change significantly during the experiment, Eq. (2) can be rewritten as

$$
\begin{aligned}
E= & E_{\mathrm{Ox}_{(\mathrm{o})} \mid \operatorname{Red}_{(\mathrm{o})}^{-}}^{(}+\Delta \phi_{\mathrm{aq}^{\mathrm{C}^{\theta}}}^{\mathrm{o}^{+}}+\frac{R T}{F} \ln \left(c\left(\mathrm{Cat}^{+}\right)_{(\mathrm{aq})}\right) \\
& +\frac{R T}{F} \ln \left(\frac{c(\mathrm{Ox})_{(\mathrm{o})}}{c\left(\operatorname{Red}^{-}\right)_{(\mathrm{o})} c\left(\mathrm{Cat}^{+}\right)_{(\mathrm{o})}}\right) .
\end{aligned}
$$

Due to the requirements of maintaining the electroneutrality of the organic phase, it holds that $c\left(\operatorname{Red}^{-}\right)_{(\mathrm{o})}=$ $c\left(\mathrm{Cat}^{+}\right)_{(\mathrm{o})}$. The mass conservation law in respect to the organic phase leads to $c\left(\operatorname{Red}^{-}\right)_{(\mathrm{o})}+c(\mathrm{Ox})_{(\mathrm{o})}=c^{*}(\mathrm{Ox})_{(\mathrm{o})}$, where $c^{*}(\mathrm{Ox})_{(\mathrm{o})}$ is the initial concentration of the reducible compound in the organic phase. By definition, for $c\left(\operatorname{Red}^{-}\right)_{(\mathrm{o})}=c(\mathrm{Ox})_{(\mathrm{o})}$, the formal potential $\left(E_{\mathrm{c}}^{\theta^{\prime}}\right)$ of the system is acquired

$$
\begin{aligned}
E_{\mathrm{c}}^{\theta^{\prime}}= & E_{\mathrm{Ox}_{(\mathrm{o})} \mid \operatorname{Red}_{(\mathrm{o})}^{-}}^{\theta}+\Delta \phi_{\mathrm{aq}^{\mathrm{o}^{\theta}}}^{\mathrm{Cat}^{+}}+\frac{R T}{F} \ln \left(c\left(\mathrm{Cat}^{+}\right)_{(\mathrm{aq})}\right) \\
& +\frac{R T}{F} \ln \left(\frac{2}{c^{*}(\mathrm{Ox})_{(\mathrm{o})}}\right) .
\end{aligned}
$$

Eq. (3) shows that the formal potential depends via $\Delta \phi_{\mathrm{aq} \mathrm{Cat}^{+}}^{\mathrm{o}^{\theta}}$ on the nature of the cations in the aqueous solution. Further, for a given cation, the formal potential should shift about $60 \mathrm{mV}$ in positive direction per decade of increasing the concentration of transferable cations in the aqueous phase. This feature taken together with the stability of the voltammograms during consecutive cycling (see inset of Scheme 1) shows whether the entire reaction at the three-phase arrangement proceeds as described by reaction (I) or not. Fe(III)TPP-Cl does not dissociate in NB so that the chloride ions do not leave the organic phase upon reduction of $\mathrm{Fe}(\mathrm{III})$ to $\mathrm{Fe}(\mathrm{II})$. Resistance measurements of pure NB and of $0.1 \mathrm{~mol} / 1$ solution of $\mathrm{Fe}(\mathrm{III})-\mathrm{TPP}-\mathrm{Cl}$ in NB showed in both cases an identical resistance of $5 \mathrm{M} \Omega$, indicating that no dissociation of $\mathrm{Fe}$ (III)-TPP-Cl occurs. If $\mathrm{Fe}(\mathrm{III})-\mathrm{TPP}-\mathrm{Cl}$ dissociated in $\mathrm{NB}$, the reduction of $\mathrm{Fe}(\mathrm{III})$-TPP would always be followed by the expulsion of chlorides from NB to water phase since the standard Gibbs energy of chloride expulsion from NB to water is $-37 \mathrm{~kJ} / \mathrm{mol}$ [2]. In that case the peak potentials of the SW voltammograms will be independent on the nature of cations in the aqueous phase, what is obviously not the case. The electrochemical reduction of Fe(III)-TPP$\mathrm{Cl}$ dissolved in nitrobenzene and immersed in aqueous chloride solutions (or nitrate in the case of $\mathrm{Tl}^{+}$) of different cations gives rise to well developed electrochemically reversible square-wave (SW) and cyclic voltammograms. The potential separation between the cathodic and anodic peaks of the cyclic voltammogams 
varied from 46 to $88 \mathrm{mV}$, by changing the scan rate from 10 to $100 \mathrm{mV} / \mathrm{s}$ (see Fig. 2), while the ratio between the cathodic and anodic peak currents changes from 1.15 to 0.90 for scan rates of 10 and $400 \mathrm{mV} / \mathrm{s}$, respectively. The variation of the potential separation between the cathodic and anodic peaks is most probably due to an increased ohmic drop effect by increasing the scan rate. The mid-peak potential of the cyclic voltammograms is almost constant and changes by just $14 \mathrm{mV}$ for the scan rate being changed from 20 to $600 \mathrm{mV} / \mathrm{s}$ (results not shown). All these features prove the electrochemical reversibility of the studied system. In Fig. 1 several normalized SW voltammograms recorded are showed for different cations present in the aqueous solutions. Since no electrolyte is deliberately added to the organic phase, the reduction of $\mathrm{Fe}(\mathrm{III})$-TPP-Cl can occur only at the line where the three phases are in intimate contact, i.e., at the three-phase junction line, and the reaction will advance towards the centre of the droplet [30] as a consequence of activation of the electrode surface due to the increasing conductivity of nitrobenzene due to the generation of the ionic reaction products. According to the recent publications of Aoki et al. [31] and Compton and co-workers [32], the reaction is actually confined to the three-phase junction only when large scan rates are used. For lower scan rates, the diffusion of the products in the organic phase leads to an activation of the organic layer up to about $0.23 \mu \mathrm{m}$ [31]. From Fig. 1 it is obvious that the more hydrophilic the cations in the aqueous phase are, i.e., the more negative the value of $\Delta \phi_{\mathrm{ag}^{\mathrm{Na}}}^{\mathrm{Nat}^{+}}$is, the more negative is the peak potential of the SW voltammograms and vice versa, strictly as predicted by Eq. (3). Further, the dependencies of the peak potentials of the SW voltammetric responses vs. the logarithm of the concentration of the transferable cations in the aqueous

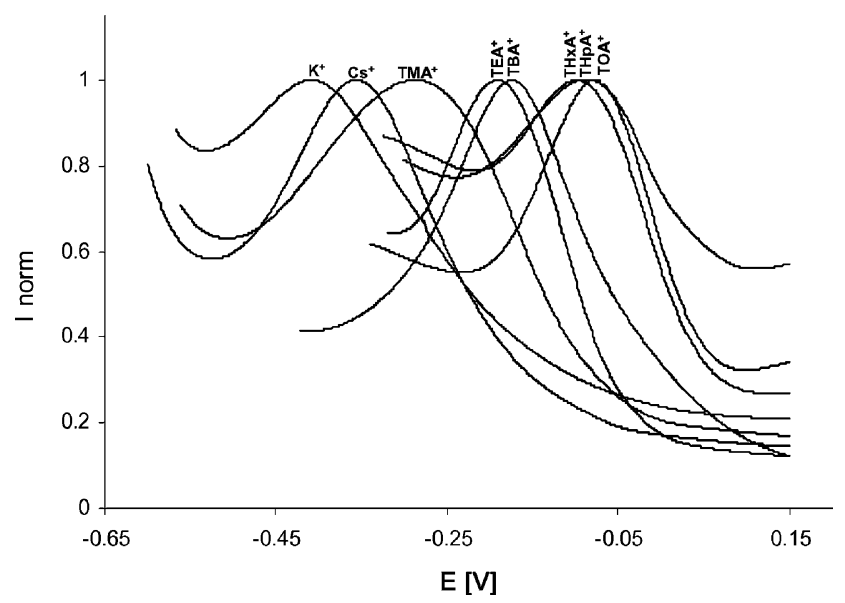

Fig. 1. Normalized square-wave voltammetric responses for the redox reaction of $\mathrm{Fe}(\mathrm{III})-\mathrm{TPP}-\mathrm{Cl}$ in the NB droplet followed by the transfer of cations from the aqueous solutions. Currents were normalised with respect to the peak current values, separately for each response. The concentration of cations was $1.0 \mathrm{~mol} / \mathrm{l}$ in all cases. solutions gave slopes of $60-50 \mathrm{mV}$ (in case of transfer of $\mathrm{TBA}^{+}$(tetrabuthyl ammonium) and TEA ${ }^{+}$(tetraethyl ammonium) cations), which is close to the values predicted by Eq. (3).

A fairly good correlation (data not shown) between the peak potentials of the SW voltammetric responses obtained by three-phase electrode approach when $\mathrm{K}^{+}$, $\mathrm{Rb}^{+}, \mathrm{Tl}^{+}, \mathrm{Cs}^{+}, \mathrm{TMA}^{+}$(tetramethyl ammonium), and $\mathrm{TEA}^{+}$were transferred from water to NB, and their standard potentials of transfer across the water|NB interface was observed (the last values were taken from [33]). However, the slope of $E_{\mathrm{c}}^{\theta^{\prime}}$ vs. $\Delta \phi_{\mathrm{aq} \mathrm{Cat}^{+}}^{\mathrm{NB}^{\theta}}$ was 0.84 instead of 1 (when all cations are taken into account, the slope is 0.73). Most probably, the reason for this inconsistency is the inaccuracy of the previously determined standard potentials of cation transfer. In the literature there are large deviations among the $\Delta \phi_{\mathrm{aq}}^{\mathrm{NB}^{\theta}}{ }^{+}$ values provided by different authors (see Table 1). Therefore, it is clear why the slope of the dependence of our $E_{\mathrm{c}}^{\theta^{\prime}}$ values vs. the literature data of $\Delta \phi_{\mathrm{aq} \mathrm{Cat}^{+}}^{\mathrm{NB}^{+}}$is not as predicted by Eq. (3). Similar experiments were performed with $\mathrm{Fe}$ (III)-TPP-Cl dissolved in 1,2-DCE. In the case of $\mathrm{TBA}^{+}, \mathrm{TEA}^{+}, \mathrm{TMA}^{+}, \mathrm{Cs}^{+}, \mathrm{K}^{+}, \mathrm{Tl}^{+}$, and $\mathrm{Rb}^{+}$again a linearity between the $E_{\mathrm{f}}$ and $\Delta \phi_{\mathrm{aqCat}}^{\mathrm{DCE}^{+}}$ values was observed, however, the slope was 0.53 (data not shown). Again, the reason for this deviation is the large difference between the $\Delta \phi_{\mathrm{aqCat}^{+}}^{\mathrm{DCE}}$ values provided by different authors (see Table 1).

Keeping in mind these discrepancies between the literature data for $\Delta \phi_{\mathrm{aq}^{\theta}}^{\mathrm{o}^{\theta}}{ }^{+}$, we determined the standard redox potential of the $\mathrm{Fe}(\mathrm{III})-\mathrm{TPP}-\mathrm{Cl} /[\mathrm{Fe}(\mathrm{II})-\mathrm{TPP}-\mathrm{Cl}]^{-}$ couple in NB by non-aqueous voltammetric measurements. For this purpose the formal redox potential of $\mathrm{Fe}(\mathrm{III})-\mathrm{TPP}-\mathrm{Cl}$ was measured in NB solution containing $10^{-2} \mathrm{~mol} / 1 \mathrm{TbutN}^{+}$hexafluorophosphate as supporting electrolyte, in the presence of ferrocene $(\mathrm{Fc})$ as an internal standard. Since the standard redox potential of ferrocene in NB is known from the literature [41], from the differences of the formal potentials of the $\mathrm{Fe}(\mathrm{III})$ TPP-Cl/[Fe(II)-TPP-Cl] $]^{-}$and $\mathrm{Fc}^{+} / \mathrm{Fc}$ couples we have determined the standard redox potential of the Fe(III)TPP-Cl/[Fe(II)-TPP-Cl] $]^{-}$couple in NB, which was

Table 1

Literature data of the standard transfer potentials of some cations across the water|NB and water|DCE interface

\begin{tabular}{lll}
\hline Cation & $\Delta \phi_{\mathrm{aq} \mathrm{Cat}^{+}}^{\mathrm{NB}^{\theta}}(\mathrm{V})$ & $\Delta \phi_{\mathrm{aq} \mathrm{Cat}^{+}}^{\mathrm{DCE}^{\theta}}(\mathrm{V})$ \\
\hline $\mathrm{Cs}^{+}$ & $-0.125[34]$ & $-0.260[37]$ \\
& $-0.185[35]$ & $-0.385[38]$ \\
$\mathrm{TEA}^{+}$ & $+0.040[33]$ & - \\
& $+0.075[36]$ & \\
$\mathrm{TBA}^{+}$ & $+0.240[37]$ & $+0.170[37]$ \\
& $+0.320[2]$ & $+0.305[38]$ \\
$\mathrm{K}^{+}$ & - & $-0.465[40]$ \\
& - & $-0.580[39]$ \\
$\mathrm{Na}^{+}$ & - & $-0.230[36]$ \\
& & $-0.590[39]$ \\
\hline
\end{tabular}


found to be $-0.260 \mathrm{~V}$ vs. $\mathrm{Ag} / \mathrm{AgCl}$ (sat. $\mathrm{NaCl}$ ). The formal potentials of both couples were independent of the supporting electrolytes present in NB. Using the determined value of the standard potential of $\mathrm{Fe}(\mathrm{III})$ TPP-Cl/[Fe(II)-TPP-Cl] $]^{-}$in NB, we estimated the standard Gibbs energies of cation transfer across the water|NB interface according to Eq. (3). The estimated $\Delta G_{\mathrm{aqCat}^{+}}^{\mathrm{NB}^{\theta}}$ data together with the literature data are given in Table 2. Fig. 2 depicts the comparison between the standard Gibbs energies of transfer of the cations determined by our approach, and the corresponding values estimated according to the simple Born theory [1]. The first linear part in Fig. 2 corresponds to the cations $\mathrm{K}^{+}$, $\mathrm{Rb}^{+}, \mathrm{Cs}^{+}, \mathrm{Tl}^{+}$, and $\mathrm{TMA}^{+}\left(R^{2}=0.997\right)$, while the second one corresponds to the values of the alkyl ammonium cations $\left(\mathrm{TMA}^{+}, \mathrm{TEA}^{+}, \mathrm{TBA}^{+}, \mathrm{THxA}^{+}\right.$ (tetrahexyl ammonium), $\mathrm{THpA}^{+}$(tetraheptyl ammonium), and $\mathrm{TOA}^{+}$(tetraoctyl ammonium) $\left(R^{2}=0.998\right)$. The reason for the differences in the slopes between both linear parts is most probably due to charge delocalisation because of the positive inductive effect of the alkyl groups in tetraalkyl ammonium cations. These effects are not taken into account in the simple electrostatic Born theory. The differences in the slopes cannot be ascribed to ion association since the rather large dielectric constant of NB does not allow significant ion paring effects to occur. It is important to note that a very bad or even no correlation exists between the $\Delta G_{\mathrm{aq} \mathrm{Cat}^{+}}^{\mathrm{NB}^{\theta}}$, values of tetraalkyl ammonium cations provided by other authors (see Table 2) and the $\Delta G_{\mathrm{aqCat}^{+}}^{\mathrm{NB}^{\theta}}$, values estimated according to the Born theory. Although this does not confirm the correctness of our results, it is still very much supporting our data. Fig. 3 shows that there exists a good correlation between the number of carbon atoms in the single alkyl chain of the ammonium ions and the Gibbs energies of transfer of these ions. This dependence resembles a similar one for $n$-carboxylate anions [13].

Finally, it is worth noticing that due to the large ascending currents arising from the reduction of nitro-

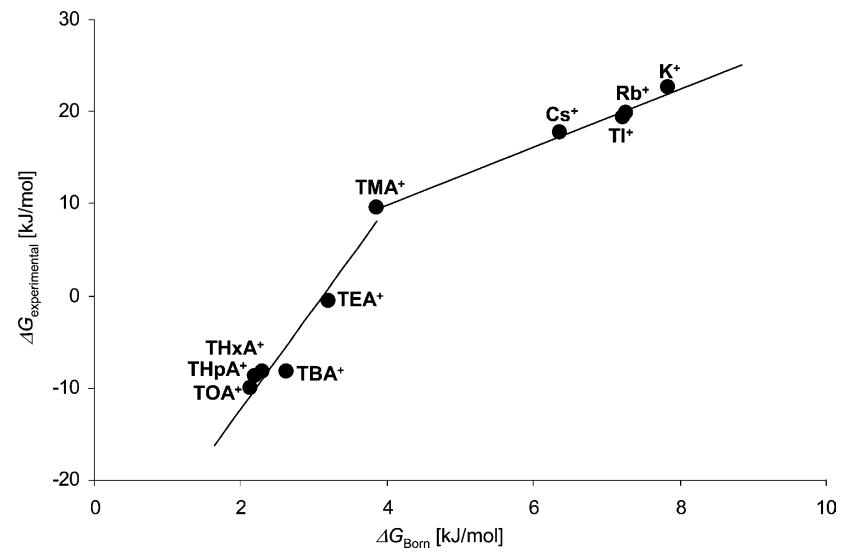

Fig. 2. Comparison between $\Delta G_{\mathrm{WCat}^{+}}^{\mathrm{NB}^{\theta}}$ values determined with the three-phase electrode and the corresponding values estimated using the simple electrostatic Born theory.

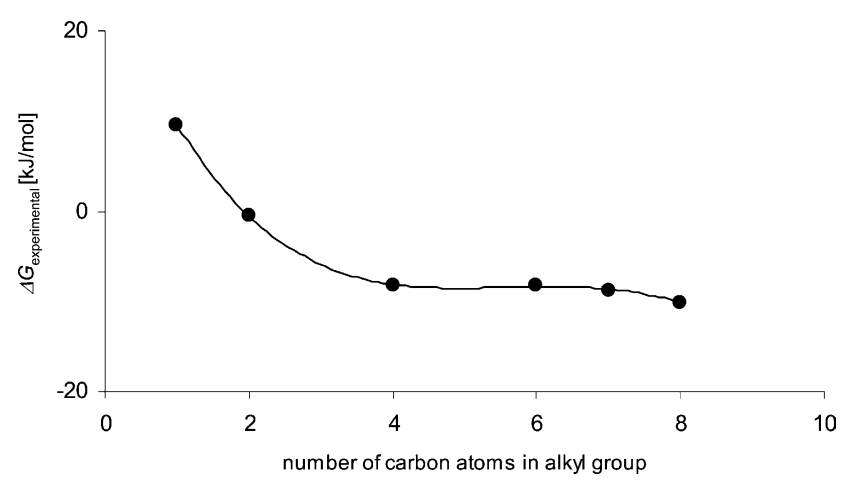

Fig. 3. Correlation between the number of carbon atoms in the single alkyl chain and Gibbs energies of transfer of the corresponding tetraalkyl ammonium ions.

benzene at potentials more negative than $-0.45 \mathrm{~V}$ (see Fig. 1), it is not possible to study the transfer of cations the standard Gibbs energies of which are higher than 23 $\mathrm{kJ} / \mathrm{mol}$ (such as $\mathrm{Li}^{+}, \mathrm{Na}^{+}$, and most of the amino acid cations).

Table 2

Standard Gibbs energies of transfer of cations across the water|NB interface estimated by our approach and compared with the values of other authors

\begin{tabular}{|c|c|c|c|c|}
\hline Cation & $\begin{array}{l}\Delta G_{\mathrm{aq} \mathrm{Cat}^{+}}^{\mathrm{N}^{\theta}}\left(\mathrm{kJ} \mathrm{mol}{ }^{-1}\right) \\
\text { (our approach) }\end{array}$ & $\Delta G_{\mathrm{aq} \mathrm{Cat}^{+}}^{\mathrm{NB}^{\theta}}\left(\mathrm{kJ} \mathrm{mol}^{-1}\right)[2]$ & $\Delta G_{\mathrm{aq}^{\mathrm{Cat}}}^{\mathrm{NB}^{\theta}}\left(\mathrm{kJ} \mathrm{mol}^{-1}\right)[42]$ & $\Delta G_{\mathrm{aq} \mathrm{Cat}^{+}}^{\mathrm{NB}^{\theta}}\left(\mathrm{kJ} \mathrm{mol}^{-1}\right)[33]$ \\
\hline $\mathrm{K}^{+}$ & 22.65 & 21.00 & 23.40 & 21.00 \\
\hline $\mathrm{Rb}^{+}$ & 19.80 & 19.00 & 19.2 & 19.00 \\
\hline $\mathrm{Tl}^{+}$ & 19.30 & 18.00 & 18.00 & 19.40 \\
\hline $\mathrm{Cs}^{+}$ & 17.80 & 18.00 & 15.40 & 12.50 \\
\hline $\mathrm{TMA}^{+}$ & 9.60 & 4.00 & 3.40 & 4.80 \\
\hline $\mathrm{TEA}^{+}$ & -0.50 & -5.00 & -5.70 & -4.80 \\
\hline $\mathrm{TBA}^{+}$ & -8.20 & -31.00 & -24.00 & -24.00 \\
\hline $\mathrm{THxA}^{+}$ & -8.21 & - & - & - \\
\hline $\mathrm{THpA}^{+}$ & -8.78 & - & - & - \\
\hline $\mathrm{TOA}^{+}$ & -10.09 & - & - & - \\
\hline
\end{tabular}

\footnotetext{
${ }^{\mathrm{a}}$ Estimated using the value of $E_{\mathrm{Fe}(\mathrm{III}) \mathrm{TPP} / \mathrm{Fe}(\mathrm{II}) \mathrm{TPP}-(\mathrm{NB})}^{0}=-0.260 \mathrm{~V}$ (vs. $\left.\mathrm{Ag} / \mathrm{AgCl}\right)$.
} 


\section{Conclusions}

In this work we succeeded to measure the standard Gibbs energies of transfer of cations with the help of a three-phase electrode, completely analogously to the previously reported case of anion transfer [12]. The new method will be applied to determine these data for many more cations. Yet, a careful comparison of the results with the data obtained with other techniques will be necessary. Moreover, it is essential to find out the limitations of the new approach with respect to solvents and cations. Certainly also a search will follow for other electroactive reagents that track cations into the organic phase, possibly even better than Fe(III)-TPP-Cl.

\section{Acknowledgements}

F. Scholz acknowledges support by Deutsche Forschungemeinschaft (DFG) and Fonds der Chemischen Industrie (FCI), R. Gulaboski thanks Deutscher Akademischer Austauschdienst (DAAD) for provision of a Ph.D. scholarship and K. Caban acknowledges support by DAAD.

\section{References}

[1] A.G. Volkov, Liquid-Liquid Interfaces in Chemical, Biological, and Pharmaceutical Applications, Marcel Dekker, New York, Basel, 2001

[2] Y. Marcus, Ion Properties, Marcel Dekker, New York, 1997.

[3] H.H. Girault, D.J. Schiffrin, Electrochemistry of liquid-liquid interfaces, in: A.J. Bard (Ed.), Electroanalytical Chemistry, A Series of Advances, vol. 15, Marcel Dekker, New York, 1989, pp. $1-132$.

[4] F. Reymond, D. Fermin, H.J. Lee, H.H. Girault, Electrochim. Acta 45 (2000) 2647.

[5] V. Chopineaux-Courtois, F. Reymond, G. Bouchard, P.-A. Carrupt, B. Testa, H.H. Girault, J. Am. Chem. Soc. 121 (1999) 1743.

[6] A. Mälkiä, P. Liljeroth, K. Kontturi, Electrochem. Commun. 5 (2003) 473.

[7] A. Mälkiä, P. Liljeroth, K. Kontturi, J. Phys. Chem. B 105 (2001) 10884

[8] J.A. Manzanares, R.A.M. Allen, K. Kontturi, J. Electroanal. Chem. 483 (2000) 188.

[9] S.M. Ulmeanu, H. Jensen, Z. Samec, G. Bouchard, P.-A. Carrupt, H.H. Girault, J. Electroanal. Chem. 530 (2002) 10.

[10] V. Gobry, S.M. Ulmeanu, F. Reymond, G. Bouchard, P.-A. Carrupt, B. Testa, H.H. Girault, J. Am. Chem. Soc. 123 (2001) 10684.

[11] V. Chopineaux-Courtois, F. Reymond, G. Bouchard, P.-A. Carrupt, H.H. Girault, J. Am. Chem. Soc. 121 (1999) 1743.

[12] F. Scholz, Š. Komorsky-Lovrić, M. Lovrić, Electrochem. Commun. 2 (2000) 112.
[13] R. Gulaboski, K. Riedl, F. Scholz, Phys. Chem. Chem. Phys. 5 (2003) 1284.

[14] Š. Komorsky-Lovrić, K. Riedl, R. Gulaboski, V. Mirčeski, F. Scholz, Langmuir 18 (2002) 8000, and 19 (2003) 3090.

[15] R. Gulaboski, V. Mirčeski, F. Scholz, Electrochem. Commun. 4 (2002) 277.

[16] R. Gulaboski, F. Scholz, J. Phys. Chem. B 107 (2003) 5650

[17] R. Gulaboski, V. Mirčeski, F. Scholz, Amino Acids 24 (2003) 149.

[18] F. Scholz, R. Gulaboski, V. Mirčeski, P. Langer, Electrochem. Commun. 4 (2002) 659.

[19] V. Mirčeski, R. Gulaboski, F. Scholz, Electrochem. Commun. 4 (2002) 813.

[20] G. Bouchard, A. Galland, P.-A. Carrupt, R. Gulaboski, V. Mirčeski, F. Scholz, H.H. Girault, Phys. Chem. Chem. Phys. 5 (2003) 3748 .

[21] A.J. Wain, N.S. Lawrence, P.R. Greene, J.D. Wadhawan, R.G. Compton, Phys. Chem. Chem. Phys. 9 (2003) 1867.

[22] U. Schröder, R.G. Compton, F. Marken, S.D. Bull, S.G. Davies, S. Gilmour, J. Phys. Chem. B 105 (2001) 1344.

[23] U. Schröder, J. Wadhawan, R.G. Evans, R.G. Compton, B. Wood, D.J. Walton, R.R. France, F. Marken, P.C. Bulman Page, C.M. Hayman, J. Phys. Chem. B 106 (2001) 8697.

[24] J.D. Wadhawan, R.G. Evans, R.G. Compton, J. Electroanal Chem. 533 (2002) 71 .

[25] F. Marken, R.D. Webster, St.D. Bull, St.G. Davies, J. Electroanal. Chem. 437 (1997) 209.

[26] C. Shi, C. Anson, J. Phys. Chem. B 102 (1998) 9850.

[27] T.D. Chung, F.C. Anson, Anal. Chem. 73 (2001) 337.

[28] C. Shi, C. Anson, J. Phys. Chem. B 105 (2001) 1047.

[29] S. Ulmeanu, H.J. Lee, D.J. Fermin, H.H. Girault, Y. Shao, Electrochem. Commun. 3 (2001) 219.

[30] M. Donten, Z. Stojek, F. Scholz, Electrochem. Commun. 4 (2002) 324.

[31] (a) P. Tasakorn, J. Chen, K. Aoki, J. Electroanal. Chem. 533 (2002) 119 ;

(b) K. Aoki, P. Tasakorn, J.Y. Chen, J. Electroanal. Chem. 542 (2003) 51.

[32] Q. Fulian, J.C. Ball, F. Marken, R.G. Compton, A.C. Fisher, Electroanal. 12 (2000) 1012.

[33] H.H. Girault, Electrochemical Data Base. Available from $<$ http:// dcwww.epfl.ch/cgi-bin/LE/DB/InterrDB.pl>.

[34] A.F. Danil de Namor, T. Hill, J. Chem. Soc., Fraraday Trans. 79 (1983) 2713.

[35] Z. Samec, V. Marecek, M.P. Colombini, J. Electroanal. Chem. 257 (1988) 147.

[36] T. Wandlowski, V. Marecek, Z. Samec, Electrochim. Acta 35 (1990) 1173

[37] B. Hundhammer, T. Solomon, J. Electroanal. Chem. 157 (1983) 19.

[38] Y. Shao, A.A. Stewart, H.H. Girault, J. Chem. Soc., Faraday Trans. 87 (1991) 2593.

[39] A. Sabela, V. Marecek, Z. Samec, R. Fuoco, Electrochim. Acta 37 (1992) 231.

[40] M.H. Abraham, A.F. Danil de Namor, J. Chem. Soc., Fraraday Trans. 72 (1976) 955.

[41] I. Noviandri, N.K. Brown, S. Douglas, T.P. Fleming, T. Gulyas, P.A. Lay, A.F. Masters, L. Philips, J. Phys. Chem. B 103 (1999) 6713

[42] (a) J. Rais, Coll. Czech. Chem. Commun. 36 (1970) 3253; (b) J. Rais, P. Selucky, A. Kyrs, J. Inorg. Nucl. Chem. 38 (1976) 1376. 